\title{
Development of Exchangeable Fins for Heat Transfer Enhancement in Existing Shell and Tube Heat Exchangers*
}

\author{
Hiroyuki TANAKA**, Koichi NAKASO**, Naoyuki FURUMOTO***, \\ Tsuguhiko NAKAGAWA**** and Jun FUKAI** \\ ${ }^{* *}$ Department of Chemical Engineering, Graduate School of Engineering, Kyushu University, \\ 744 Motooka, Nishi-ku, Fukuoka, Japan \\ E-mail: jfukai@chem-eng.kyushu-u.ac.jp \\ ***JFE Engineering, \\ 2-1 Suehiro-cho, Tsurumi-ku, Yokohama, Japan \\ ****Department of System Engineering, Okayama Prefectural University, \\ 111 Kuboki, Soja, Okayama, Japan
}

\begin{abstract}
To conventionally extend heat transfer area in shell-and-tube heat exchangers, a method is proposed where sheet materials with high thermal conductivities are stretched among tubes. The numerical simulations are carried out to predict the performance of heat exchanger with or without the sheets. As a result, it is found that thermal contact resistances between the sheet and tubes rather than thickness and thermal conductivity of the sheet influence overall heat transfer coefficient. In the experiments, the carbon fibers clothes $\left(27 \mathrm{~W} \mathrm{~m}^{-1} \mathrm{~K}^{-1}\right)$ are pass zigzag though the tubes whose pitch is $20 \mathrm{~mm}$. The heat transfer rate between hot water flowing in the tube side and air in the shell side are measured. No substantial improvement of heat transfer is unfortunately observed experimentally due to contact thermal resistance. The method proposed in this study conclusively has a potential that the heat transfer rate improves no less than a few ten percents.
\end{abstract}

Key words: Thermal Engineering, Heat Transfer Enhancement, Heat Exchanger

\section{Introduction}

The amount of energy consumption in Japan is among the highest in the world, and owing to poor domestic energy sources, approximately $80 \%$ of the energy is imported from other countries. ${ }^{(1)-(3)}$ In recent years, global environmental problems and the decrease in the levels of fossil fuels have necessitated the active saving of energy and the use of unused energy.

Improvement in heat transfer using heat exchangers has been studied for many years, and various techniques have been proposed. ${ }^{(4)-(6)}$ However, the current energy scenario demands a further improvement in heat transfer so as to achieve the required level of energy savings.

This study deals with the recovery of exhaust heat from corrosive gases. Heat transfer tubes with fins are widely used to enhance the efficiency of a heat exchanger; however, thin fins are easily corroded in the corrosive gas ambient, and once corroded, they become incapable of enhancing heat transfer. Although heat exchangers made of corrosion-resistant materials such as Inconel or titanium are available, they are costly and are therefore not widely used.

Therefore we focused on maintaining the heat exchange performance by the regular

*Received 21 Dec., 2010 (No. T1-09-0197) Japanese Original : Trans. Jpn. Soc. Mech. Eng., Vol.75, No.757, B (2009), pp.1854-1861 (Received 10 Mar., 2009) [DOI: 10.1299/jee.6.400]

Copyright $\odot 2011$ by JSME 
replacement of fins, rather than by of preventing the corrosion of fins. To be more precise, in order to enhance heat transfer in latent heat storage tanks ${ }^{(7)}$, we had proposed to use sheet with high thermal conductivities in the heat exchange tubes. By utilizing this method, the fins are easily changed.

In this study, the effect of sheet fins attached to the heat transfer tubes on the heat transfer performance of a heat exchanger was numerically investigated. In addition, the phenomenon of convective heat transfer was studied by the experiment and calculation in the temperature range where radiation heat transfer was properly negligible

\section{Nomenclature}

$A$ : heat transfer area, $\mathrm{m}^{2}$
$C_{\mathrm{p}}:$ specific heat, $\mathrm{J} / \mathrm{kgK}$
$C_{\mathrm{f}}$ : coefficient of Eq. (2)
$C_{\mathrm{H}}$ : coefficient of Eq. (4)
$D$ : tube diameter, $\mathrm{m}$

$G_{\text {max }}$ : maximum fluid mass velocity in the tube bank, $\mathrm{kg} / \mathrm{m}^{2} \mathrm{~s}$

$h$ : heat transfer coefficient, $\mathrm{W} / \mathrm{m}^{2} \mathrm{~K}$

$H$ : enthalpy, J

I: unit tensor, $\mathrm{Pa}$

$J$ : diffusion flux, $\mathrm{mol} / \mathrm{m}^{2} \mathrm{~s}$

$k$ : turbulent energy, $\mathrm{m}^{2} / \mathrm{s}^{2}$

$l$ : distance, $\mathrm{m}$

$l_{\mathrm{p}}:$ tube pitch, $\mathrm{m}$

$N$ : fin parameter

$n$ : number of tube lines in the flow direction

$P$ : pressure, $\mathrm{Pa}$

Pr: Prandtl number

$Q$ : heat transfer rate, $\mathrm{W}$

$R_{\mathrm{c}}$ : thermal contact resistance, $\mathrm{m}^{2} \mathrm{~K} / \mathrm{W}$

Re: Reynolds number

$T$ : temperature, $\mathrm{K}$

$U$ : overall heat transfer coefficient, $\mathrm{W} / \mathrm{m}^{2} \mathrm{~K}$

$V:$ flow velocity, $\mathrm{m} / \mathrm{s}$

$\delta$ : fin thickness, $\mathrm{m}$

$\Delta T_{l m}:$ logarithmic mean temperature difference, $\mathrm{K}$

$\varepsilon$ : turbulence kinetic energy dissipation rate, $\mathrm{m}^{2} / \mathrm{s}^{3}$

$\lambda$ : thermal conductivity, $\mathrm{W} / \mathrm{mK}$

$\mu$ : coefficient of viscosity, $\mathrm{Pa} \cdot \mathrm{s}$

$\mu_{\mathrm{t}}$ : coefficient of eddy viscosity, $\mathrm{m}^{2} / \mathrm{s}$

$\sigma_{\mathrm{k}}:$ turbulent Prandtl number

$\tau_{\omega}:$ shear stress, $\mathrm{N}$

$\bar{\tau}$ : stress tensor, $\mathrm{Pa}$

$\Psi$ : coefficient of Eq. (4)

Subscripts

a: air

f: fin

h: heat transfer fluid

i: inside the heat transfer tube

o: outside the heat transfer tube

t: heat transfer tube

w: wall surface of the heat transfer tube 


\section{Numerical analysis}

\subsection{Analytical model}

The target of our study is the development a cross-flow-type heat exchanger in which the heat exchange tubes are arranged in a square layout. Figure 1 shows the computational domain. The fins are arranged in contact in turn with the top and bottom tube walls (See Fig. 11 ) as shown by the dashed lines in the figure. It is assumed that the tube is very long in the longitudinal direction, and that the number of tube rows in the flow direction is very large; thus, the wall effect in the $x$ direction (longitudinal direction of tube) is ignored and the two tube rows in the $y$ direction are considered in the computational domain. Calculations of steady-state turbulence are carried out by assuming an incompressible fluid. Table 1 shows the governing equations. The use of the $k-\varepsilon$ model near the stagnation point results in the overestimation of the turbulence energy; therefore; we use the realizable $k-\varepsilon \operatorname{model}^{(8)}$ as a nonlinear eddy-viscosity model that can express anisotropic turbulence. In order to analyze the heat transfer on the surfaces of the heat transfer tube and fin, very fine mesh near wall is required; however, this is not feasible with a wall function if the first grid point is placed in the region where the logarithmic velocity distribution law can be applied in the wall boundary layer. Therefore, enhanced wall treatment (EWT), in which the grids are placed in the viscous sub-layer of the transition zone, is used ${ }^{(9)}$. In the case of a heat exchanger with fins, a steady state heat conduction in the fins are considered with the turbulence model mentioned above.

As a boundary condition, the velocity and temperature, $V_{0}$ and $T_{0}$, respectively, were assumed to be uniform at the inlet. No-slip boundary condition is considered at the heat transfer tube wall, and the temperature of the tube is assumed constant $\left(T_{\mathrm{w}}\right)$. As for the system with fins, we considered the thermal contact resistance between the heat-transfer-tube wall and the fin, and gave the following boundary condition:

$$
-\lambda_{\mathrm{w}} \frac{\partial T_{\mathrm{w}}}{\partial n}=\frac{1}{R_{\mathrm{c}}}\left(T_{\mathrm{w}}-T_{\mathrm{f}}\right)=-\lambda_{\mathrm{f}} \frac{\partial T_{\mathrm{f}}}{\partial n},
$$

where $R_{\mathrm{c}}\left(=1 / h_{\mathrm{c}}\right)$ is the thermal contact resistance. Periodic boundary conditions were considered for the velocity and temperature of the fluid at $y= \pm l_{y}$. The governing equation was discretized by the finite-volume method, the convective term was discretized by the second-order accurate upwind difference scheme, and the pressure was corrected by using the SIMPLE method. The commercially available, general-purpose software FLUENT was used for the analysis. The heat transfer coefficient $h$ was calculated from the difference between the bulk temperatures of the inlet and the outlet of the heat exchanger.

In the analysis, $l_{\mathrm{z}}=380 \mathrm{~mm}, D_{0}=10.5 \mathrm{~mm}, l_{\mathrm{Pz}}=l_{\mathrm{Py}}=20 \mathrm{~mm}, V_{0}=4.0 \mathrm{~m} / \mathrm{s}$, and $T_{\mathrm{w}}=333$ $\mathrm{K}$ were assumed for air $\left(\mathrm{P}_{\mathrm{r}}=0.71\right)$. The Reynolds number based on the maximum velocity in the tube bank $\left(=\rho V_{\max }\left(l_{\mathrm{Py}}-D_{0}\right) / \mu\right)$ is 5,500 ; this corresponds to the condition of $D_{0}=30$ $\mathrm{mm}, l_{\mathrm{Pz}}=l_{\mathrm{Py}}=57 \mathrm{~mm}$, and $V_{0}=1.4 \mathrm{~m} / \mathrm{s}$.

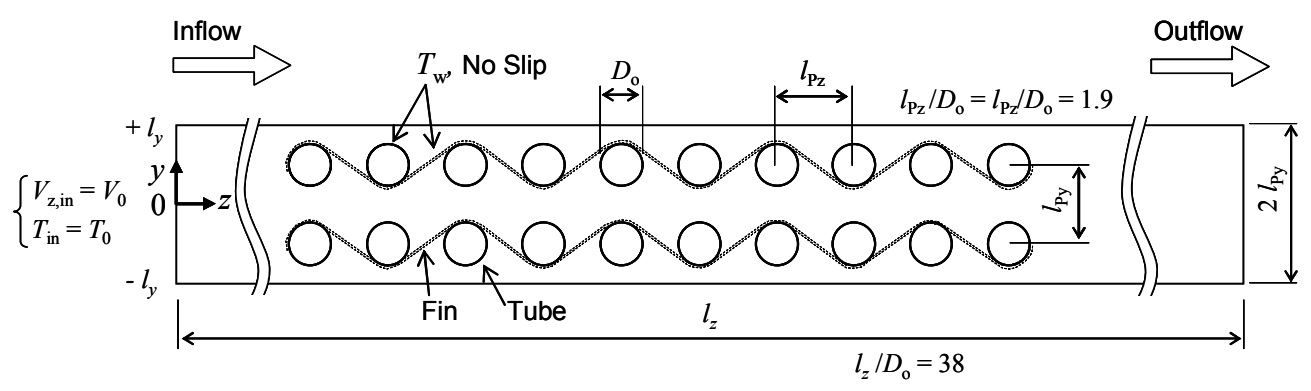

Fig.1 Computational domain. 
Table 1 Governing equations.

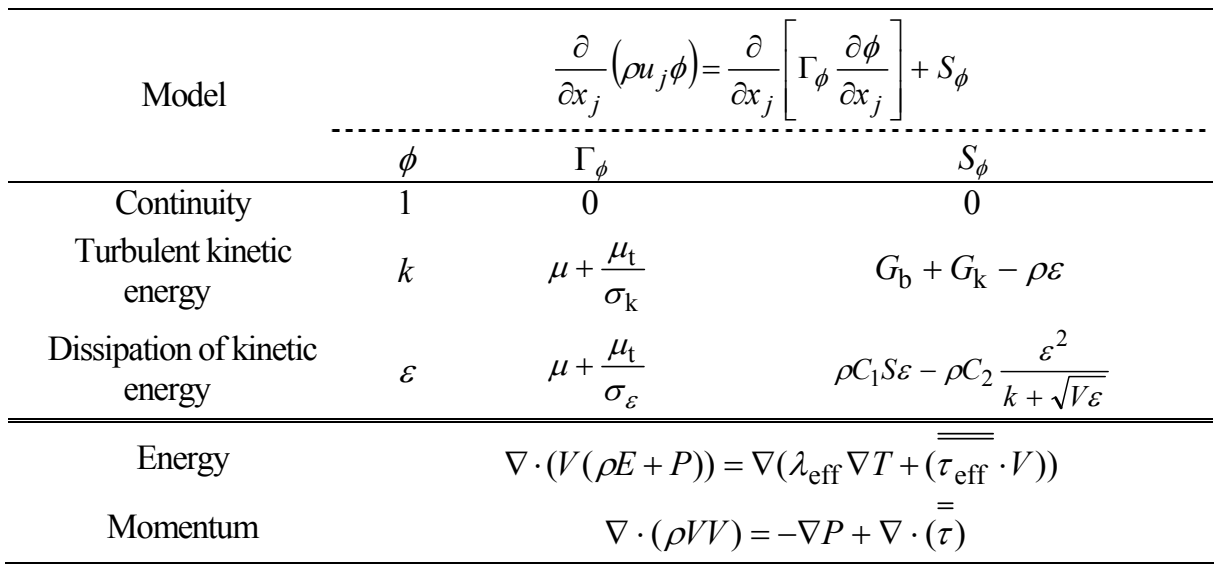

\subsection{Effect of the number of meshes}

Figure 2 shows an example of the mesh used for analysis. Figure 3 shows the result obtained from examining the relationships between the number of meshes and the pressure drop $\Delta P$ between the inlet and outlet of the heat exchanger, the temperature difference $\Delta T$, and the relative error in the mass balance and heat balance for the system without fins. The horizontal axis represents cell density (the number of meshes per unit area). The error in mass balance and the difference between the temperatures of the inlet and outlet of the heat exchanger are approximately constant, regardless of the cell density. The pressure drop increases with decreasing the cell density. This is because the effect of viscosity is considered beyond the transition layer. We use the following equation to estimate the pressure drop in the tube banks ${ }^{(10)}$

$$
\Delta P_{0}=0.334 C_{\mathrm{f}} n \frac{G_{\max }^{2}}{2 \rho} .
$$

Eq. (2) gives $\Delta P_{0}=89.9 \mathrm{~Pa}$ for our system. On the basis of this fact, the number of meshes is assumed to be 19,300 cells $/ \mathrm{cm}^{2}(\Delta P=88 \mathrm{~Pa}, \Delta T$ $=10.95 \mathrm{~K}$ ) in the following analysis.

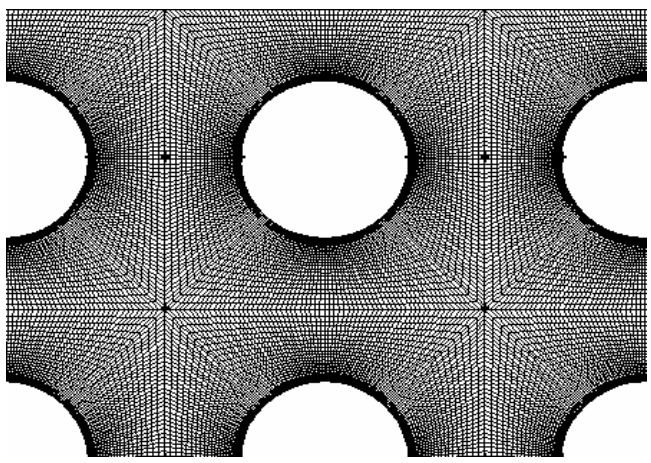

Fig.2 Typical numerical grid around tubes (19300 cells $/ \mathrm{m}^{2}$ )
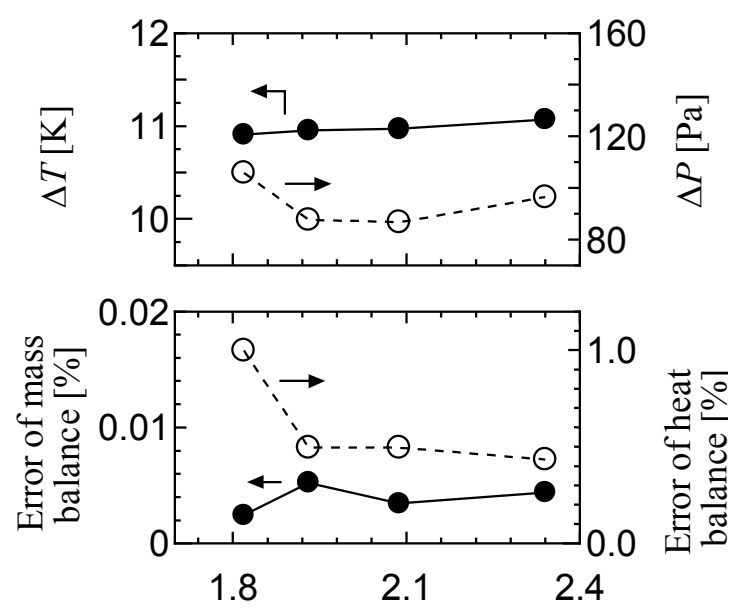

Cell density $\times 10^{4}\left[\right.$ cells $\left./ \mathrm{cm}^{2}\right]$

Fig.3 Effect of cell density on calculation errors 


\section{Numerical results}

\subsection{Thermal contact resistance between the fins and tubes}

Figure 4 shows the effect of $R_{\mathrm{c}}$ on the temperature profile. The figure indicates that fins increase the temperature difference between inlet and outlet, $\Delta T$, up to $11.7 \mathrm{~K}$ if the thermal contact resistance between the fins and tubes is negligibly small $\left(R_{\mathrm{c}}=0\right)$, while the value of $\Delta T$ was $11.0 \mathrm{~K}$ without the fins. This fact indicates an improvement in the heat transfer. On the other hand, the fluid temperature difference decreased to $10.8 \mathrm{~K}$ when the thermal contact resistance was comparatively large $\left(R_{\mathrm{c}}=1 \times 10^{-3} \mathrm{~m}^{2} \mathrm{~K} / \mathrm{W}\right)$. Note that by winding metal sheet around the cylinder, we can decrease the thermal contact resistance to below $6.5 \times 10^{-4} \mathrm{~m}^{2} \mathrm{~K} / \mathrm{W}^{(11)}$.

\subsection{Evaluation of the effect of the fin}

In this study, since our main target is to improve the efficiency of heat exchange, irrespective of the degree of increase in the heat transfer area, we adopt the product of the overall heat transfer coefficient $U$ and the heat transfer area $A$ as an index for the all-inclusive evaluation. In the numerical analysis, it is considered that $U=h$.

As shown by the dashed lines in Fig. 1, the present system is assumed to comprise heat transfer tubes with two rectangular fins. We examined the influence of the product of the thickness $\delta$ and thermal conductivity $\lambda_{\mathrm{f}}\left(\lambda_{\mathrm{f}} \delta\right)$ of a fin on the value of $U A$. The value of $\lambda_{\mathrm{f}} \delta$ is a factor of the parameter $N$ (Eq. (3)) from which the fin efficiency can be determined:

$$
N=l_{\mathrm{f}} \sqrt{\frac{2 h_{\mathrm{f}}}{\lambda_{\mathrm{f}} \delta}} .
$$

The values of $(U A) /(U A)_{0}$ are plotted in Fig. 5 as parameters of $R_{\mathrm{c}}$ and $\lambda_{\mathrm{f}} \delta$. Here, $(U A)_{0}$ is the value of $U A$ without the fins. The lines in the figure are the contour lines obtained by the linear interpolation of the calculated $(U A) /(U A)_{0}$-value. In the calculated range of this study, the effect of $R_{\mathrm{c}}$ on $(U A) /(U A)_{0}$ is more significant than that of $\lambda_{\mathrm{f}} \delta$. This implies that if the value of $R_{\mathrm{c}}$ is large, then there are cases where $(U A)<(U A)_{0}$ even when the value of $\lambda_{\mathrm{f}} \delta$ is significantly large.

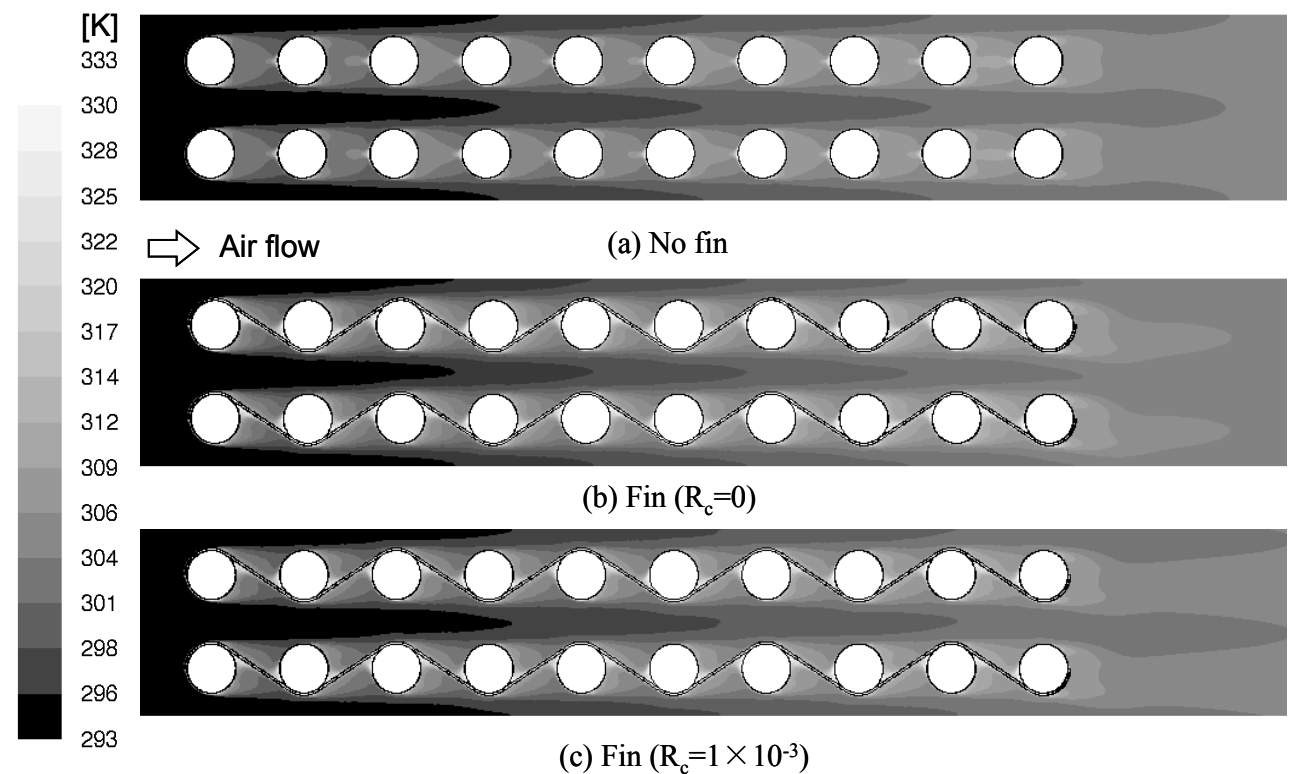

Fig.4 Contours of Static temperature on the surface of numerical region. 


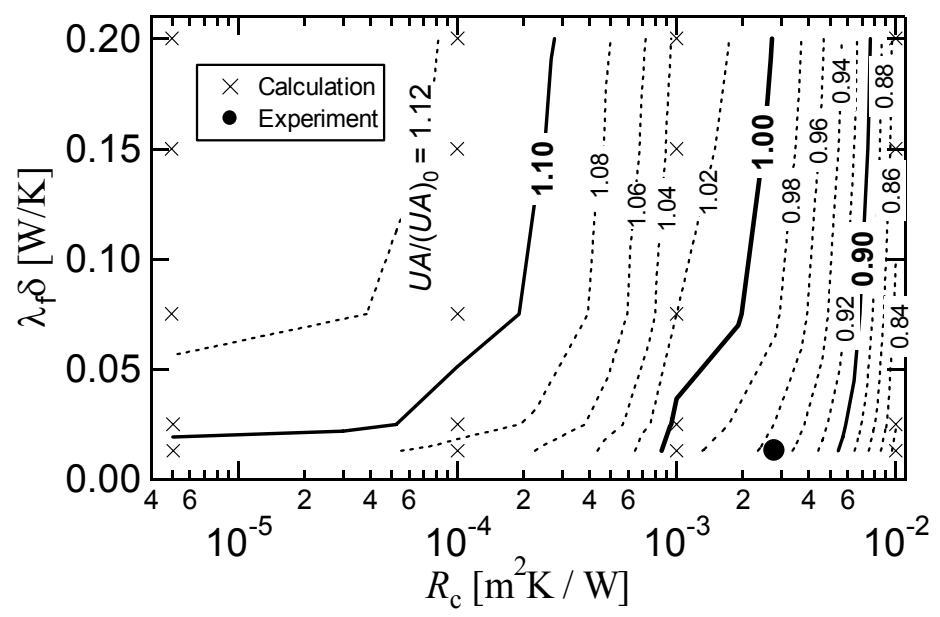

Fig.5 Summary of the calculation for the effect of $\lambda_{\mathrm{f}} \oint$ and $R_{\mathrm{c}}$ on $U A /(U A)_{0}$.

Figure 6 shows the effect of the Reynolds number on $U A$, and $\Delta P$. Where, the value of $\lambda_{\mathrm{f}} \delta$ is assumed to be $0.15 \mathrm{~W} / \mathrm{K}$ at which the fin efficiency can be considered as 1 . From the figure, $\Delta P / \Delta P_{0} \quad$ decreases and $(U A) /(U A)_{0}$ increases as $R e$ increases; that is, this sheet method is more effective as $R e$ increases.

Figure 7 shows the streamlines of average velocity. In both the cases, eddies are formed in the minimum flow area in the tube bank. Figure 8 shows the turbulence energy distribution in this domain. As shown in the figure, the distributions correspond to the two different positions from the centerline of the tube. In both the positions, there is a decrease in the turbulence energy because of the addition of fins, suggesting that the fins suppress the turbulence of flow.

\section{Experiments}

\subsection{Experimental apparatus}

Figure 9 shows the schematic of the experimental apparatus. Fig. 10 shows the details of the heat exchanger used in the experiment. The cross-sectional dimensions of the heat exchange part of the airflow are $200 \mathrm{~mm} \times 180 \mathrm{~mm}$. On the inside, heat transfer tubes made of SUS304, with an inner diameter of 7.5 $\mathrm{mm}$ and an outer diameter of $10.5 \mathrm{~mm}$,

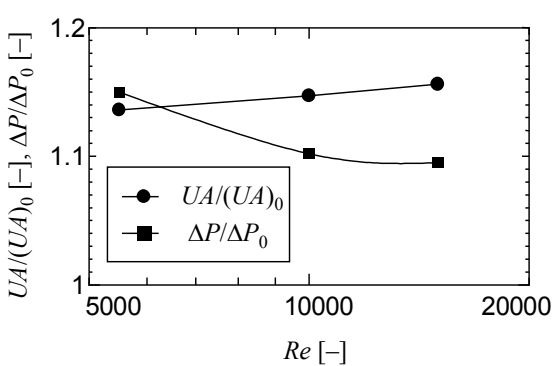

Fig.6 Effect of Reynolds number on $U A /(U A)_{0}$ and $\Delta P / \Delta P_{0}$.

$[\mathrm{m} / \mathrm{s}]$

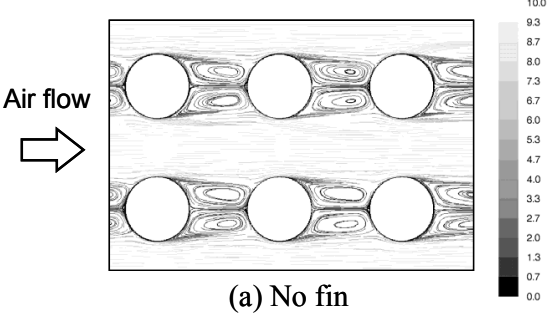

$[\mathrm{m} / \mathrm{s}]$

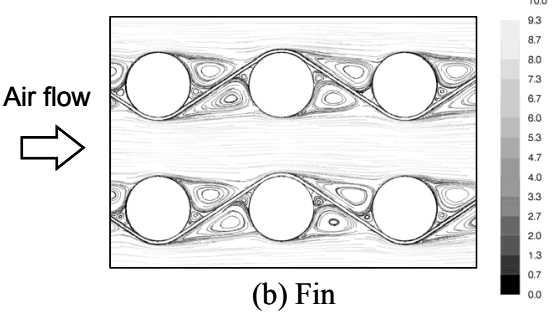

Fig.7 Path lines colored by velocity magnitude on the surface of numerical region. 

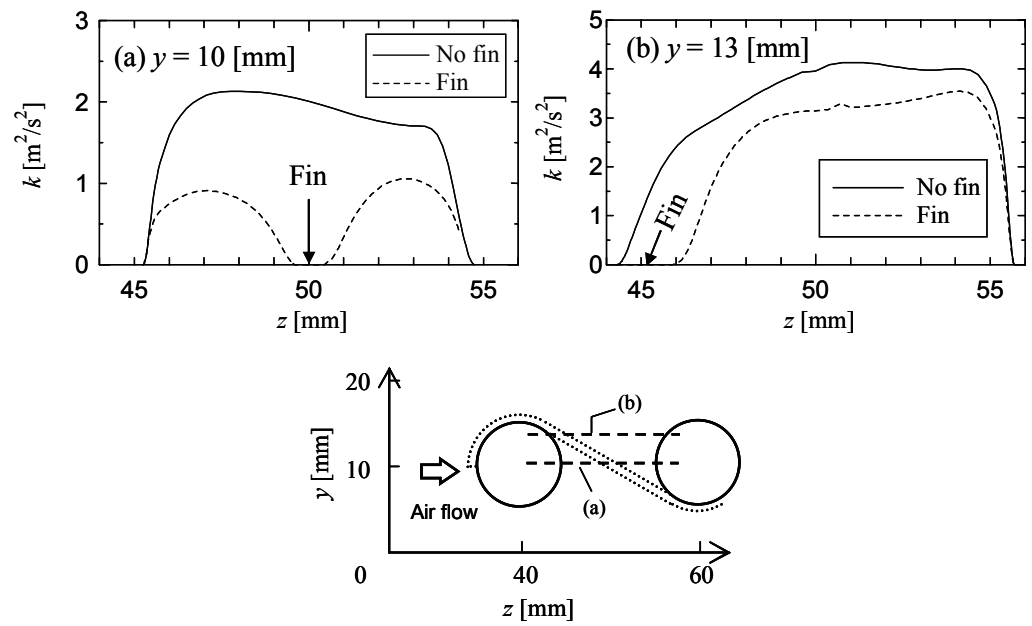

Fig.8 Turbulent kinetic energy distribution.

are arranged in the square layout with 9 columns and 10 rows. The tube pitch is $20 \mathrm{~mm}$. The air is introduced to the heat exchanger by a blower. As an entrance region of airflow, a rectangular duct of $200 \mathrm{~mm} \times$ $200 \mathrm{~mm}$ and $2,000 \mathrm{~mm}$ length is prepared in the lower part of the heat exchanger. The air heated in the heat exchange region is released to the atmosphere through the nozzle region (100 $\mathrm{mm}$ diameter) placed at a height of $600 \mathrm{~mm}$ above the heat exchange region.

Heated water, as a heat transfer fluid, is passed through the heat transfer tubes in one pass via a header. The heat transfer fluid is circulated through a constant-temperature tank in order to maintain a constant inlet temperature. In the header, a dispersion board is placed and two inlet ports are set up for the heat transfer fluid in order to ensure that the fluid is uniformly distributed across the heat transfer tubes.

The whole system, including the duct, is covered with insulation material. Rubber packing of $5 \mathrm{~mm}$ thickness is inserted between the duct and

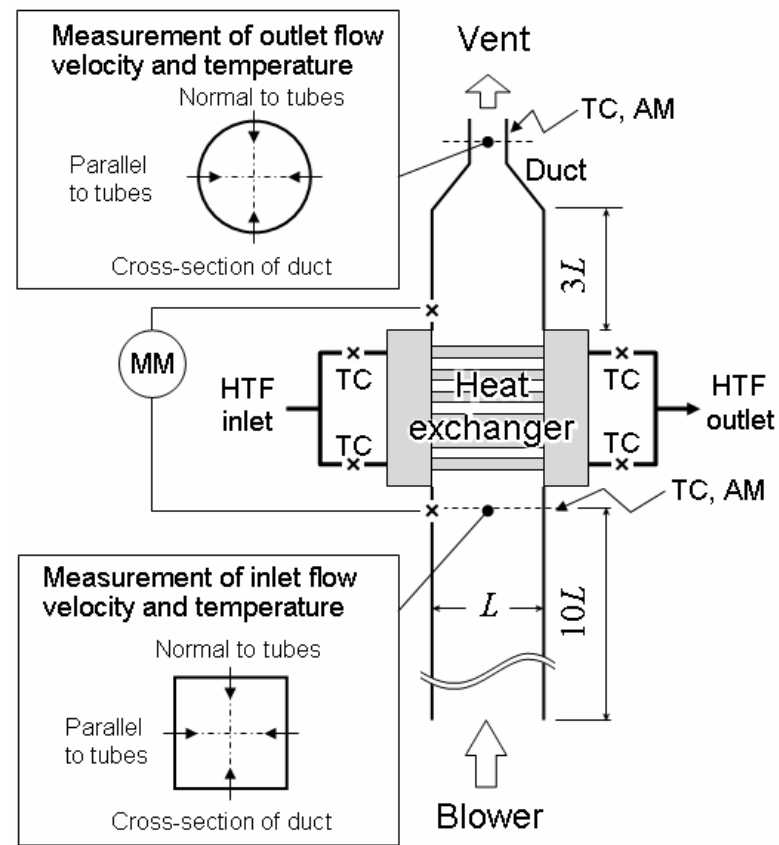

$\times$ Measurement point TC: Thermocouple AM: Anemometer MM: Manometer

Fig.9 Schematic diagram of experimental apparatus

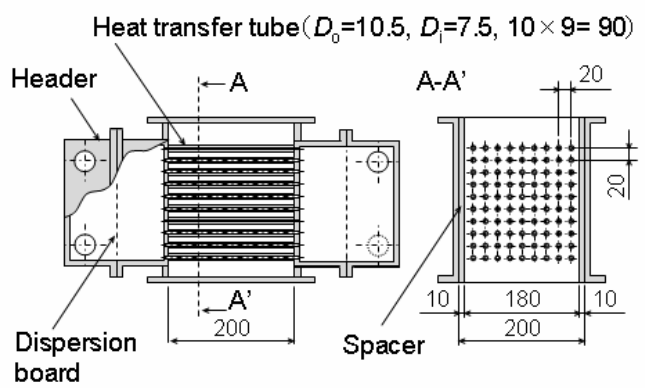

Fig.10 Schematic diagram of a heat exchanger. 
the heat exchanger. In addition, insulation material of $5 \mathrm{~mm}$ thickness is applied to the inner wall of the heat exchanger to avoid direct exchange of heat between the heat transfer fluid in the header and the air.

The temperature and the velocity of air were measured at two positions - at $120 \mathrm{~mm}$ below the lower part of the heat exchanger and at the upper part (nozzle). A T-type sheath thermocouple of outer diameter $1 \mathrm{~mm}$ was used for the temperature measurement, and a hot-wire anemometer was used for the velocity measurement; the measurement tip was horizontally moved in $10-\mathrm{mm}$ steps in order to measure the distributions of velocity and temperature. In addition, the pressure drop between two positions: $50 \mathrm{~mm}$ above the upper part and $120 \mathrm{~mm}$ below the lower part of the heat exchanger was measured by using a manometer. The flow rate of heated water was calculated from the volume of water returning to the constant-temperature tank; the measurement was made in a polyethylene container in which the water was made to flow temporarily before flowing into the tank.

The heat transfer fluid whose temperature was kept constant $\left(59-66^{\circ} \mathrm{C}\right)$ by the constant-temperature tank, was passed through the heat transfer tubes at $6.08 \times 10^{-3} \mathrm{~m}^{3} / \mathrm{s}$ $(36.5 \mathrm{~L} / \mathrm{m})$. Air at $20-27^{\circ} \mathrm{C}$ was introduced at $0.16 \mathrm{~m}^{3} / \mathrm{s}$. The temperatures of the thermocouples at the top and bottom of the heat exchanger and the pressure drop were subsequently measured after the steady state $( \pm 0.12 \mathrm{~K})$ was reached.

The Reynolds number $\left(=\rho_{\mathrm{h}} V_{\mathrm{h}} D_{\mathrm{i}} / \mu_{\mathrm{h}}\right)$ of tube side was approximately 2,400 , while the Reynolds number of shell side based on the minimum flow area was approximately 5,500. Here, the Reynolds number of tube side for the section containing heated water was set to approximately 2,400 in order to determine the heat exchange rate from the temperature difference between the inlet and outlet of the heated water. The water flow was set such that the value of $\Delta T_{\mathrm{h}}$ is approximately $0.8 \mathrm{~K}$, considering the measurement accuracy $( \pm 0.5 \mathrm{~K})$ of the thermocouple.

\subsection{Configurations of the fins}

In our method, it is necessary to pass the sheet material through the narrow space between tubes and to apply tension at both sides of the sheet material to ensure the contact between sheet material and heat transfer tube. In addition, it is desirable that the sheet material for heat transfer enhancement has high thermal conductivity. Therefore, carbon fiber sheet, which the authors used in the previous study on a latent thermal storage ${ }^{(7)}$, was utilized. The density of the carbon fiber was $2,120 \mathrm{~kg} / \mathrm{m}^{3}$, and its thermal conductivity was $190 \mathrm{~W} / \mathrm{mK}$ in the fiber direction. In addition, the thickness of the sheet was $0.5 \mathrm{~mm}$, and the density per unit area of the fiber was 0.15 $\mathrm{kg} / \mathrm{m}^{2}$. Since the porosity was 0.86 , the effective thermal conductivity of the sheet was $27 \mathrm{~W} / \mathrm{mK}$ in the fiber direction.

Figure 11 shows the configurations of the fins. The index "P" indicates that the sheet is set in parallel with the airflow, and $\mathrm{N}$ indicates that sheet is set in normal to the
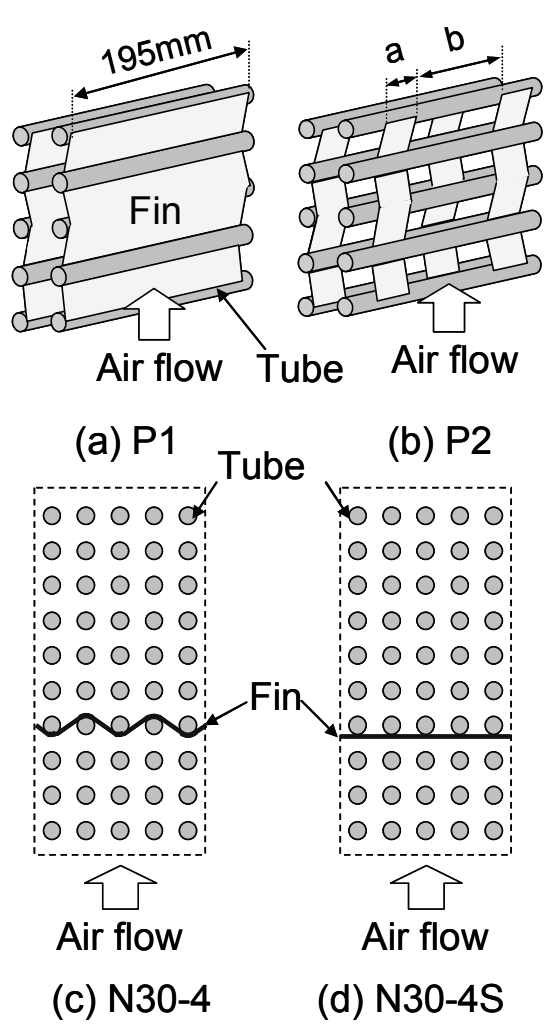

Fig.11 Configuration of fins in a heat exchanger. 
flow direction. The following three cases are investigated: (1) the flow path is covered by a sheet of width $195 \mathrm{~mm}$ (Fig. 11(a), P1); (2) the flow path is covered by two sheets of width $30 \mathrm{~mm}$ at intervals of $70 \mathrm{~mm}$ (Fig. 11(b), P2); and (3) the flow path is covered by 30 sheets of width $2 \mathrm{~mm}$ at intervals of $4 \mathrm{~mm}(\mathrm{a}=2 \mathrm{~mm}, \mathrm{~b}=4 \mathrm{~mm}$; P30 in Fig. 11(b)). Further, in the case of $\mathrm{P} 1$, the experiment was also carried out by using a cotton cloth (thickness $=0.5 \mathrm{~mm}$, thermal conductivity $=0.059 \mathrm{~W} / \mathrm{mK}^{(12)}$ ) with a lower thermal conductivity (P1-cloth).

In addition, another experiment was also carried out using the sheets same as the case P30 with normal direction to the flow (N30). The position of the sheet is determined on the basis of the Nusselt number; which is calculated by the following equation.

$$
N u=0.33 C_{\mathrm{H}} \Psi \operatorname{Re}^{0.6} \mathrm{Pr}^{0.3} \text {. }
$$

where, $C_{\mathrm{H}}$ is a coefficient that is determined from $R e$, tube diameter and pitch, and $\Psi$ is a correction factor that is determined from the number of tube rows, where $\Psi=1$ if the number of tube row is more than 10 . Figure 12 shows the effect of the number of tube row in longitudinal direction on the correction factor $\Psi$. Considering that the heat transfer coefficient gradually increases more than 3-4 rows and approaches the fixed value, following two conditions are additionally investigated. First, 30 fins with a width of $2 \mathrm{~mm}$ were placed in the fourth row of the tube bank (Fig. 11(c), N30-4); and the second, the same set of fins were placed in not only fourth row but also the seventh row (N30-4-7). In addition, as shown in Fig. 11(d), another condition was tested (N30-4S) where planar fins (width $2 \mathrm{~mm} ; 30$ pieces) were placed in contact with the fourth step of the heat transfer tubes.

Since carbon fiber sheet exhibits an anisotropic property in heat transfer, the sheet is placed so that the fibers perpendicularly cross to the heat transfer

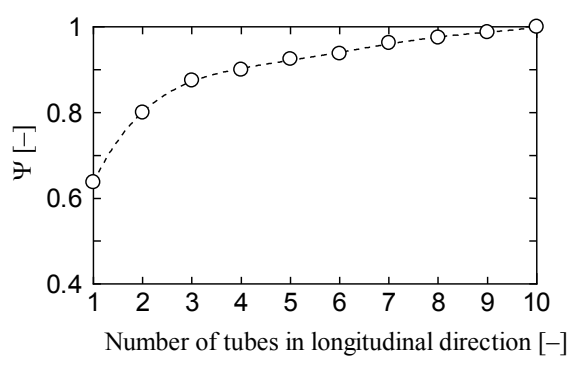

Fig.12 Effect of number of tubes in longitudinal direction on the coefficient $\Psi$. in Eq. (4). tubes.

\subsection{Experimental results}

When the difference between temperatures of the inlet and outlet is less than $1 \mathrm{~K}$ in the heat transfer tubes, the correction coefficient is close to one, and the amount of heat transfer rate $Q$ is given by the following equation:

$$
Q=U A \Delta T_{\mathrm{lm}} \text {. }
$$

where, $\Delta T_{\mathrm{lm}}$ is the logarithmic mean temperature difference. In the study of heat transfer enhancement, it is appropriate to use the Nusselt number for the shell side in the evaluation. However, in this study, the thermal resistance between the inside and outside of the tube is estimated to be approximately $1.66 \times 10^{-3} \mathrm{~K} / \mathrm{W}$, which is negligibly small when compared with the overall heat transfer resistance $(=1 / U A)$. In addition, since the purpose of this study is to improve the efficiency of heat transfer, irrespective of the heat transfer area, the value of $U A$ was exclusively used for the evaluation of the experimental results.

Figure 13 shows a typical the experimental result for the air temperature and velocity distributions at the inlet and outlet of the heat exchanger. The locations at $\pm 100 \mathrm{~mm}$ in Fig. 13(a) and those at $\pm 50 \mathrm{~mm}$ in Fig. 13(b) correspond to a distance of $1 \mathrm{~mm}$ from the wall surface. These figures obviously show that both temperature and flow velocity distributions are symmetrical about their axes. From the results, the bulk temperatures in the shell side and the heat transfer rate $Q$ are obtained. In addition, it is confirmed that the heat transfer rate determined from the temperature difference between the inlet and outlet for the tube 
side agrees with that for the shell side with an error of $3-5 \%$.

First, the experiments without the fins were repeated three times; the average results obtained were $(U A)_{0}=60.1 \mathrm{~W} / \mathrm{K}$ and $\Delta P_{0}=90 \mathrm{~Pa}$. In addition, the relative error between the experimental results was within $0.4 \%$. With the experimental conditions, the empirical equations for heat transfer coefficient (4) and pressure drop in tube bank (2) ${ }^{(10)}$ estimates $(U A)_{0}=67.7 \mathrm{~W} / \mathrm{K}$ and $\Delta P_{0}=89.9 \mathrm{~Pa}$, respectively. The experimental results agreed well with the empirical predicted results.

Figure 14 shows the average experimental results obtained for each case of the fin configurations. First, $(U A) /(U A)_{0}=0.95$ was obtained for $\mathrm{P} 1$, where the fins were placed in parallel with the air flow; clearly, significant improvement was not obtained. To confirm the heat transfer effect of the fins, the experiment was carried out by replacing the carbon fiber sheet with a cotton cloth of low thermal conductivity (thermal conductivity: $k_{\mathrm{c}}=0.059$ $\mathrm{W} / \mathrm{mK}, \mathrm{P} 1$-cloth); the value of $(U A) /(U A)_{0}$ obtained in this case was 0.80 . It was thus confirmed that the thermal conductivity of the sheet affects the over all heat transfer rate in the case of $\mathrm{Pl}$.

The experimental results for P2 and P30 (Fig. 14) show that $U A$ tends to increase as the width of the fin decreases. This suggests that the air flow between the fins improves the local heat transfer coefficient by the disturbance near the side surface of the fin. On the other hand, the ratio $\Delta P / \Delta P_{0}$ tends to decrease, this tendency agrees well with the calculation result shown in Fig. 6 .

When the fin was installed in a direction vertical to the air flow, $(U A) /(U A)_{0}<1$ was

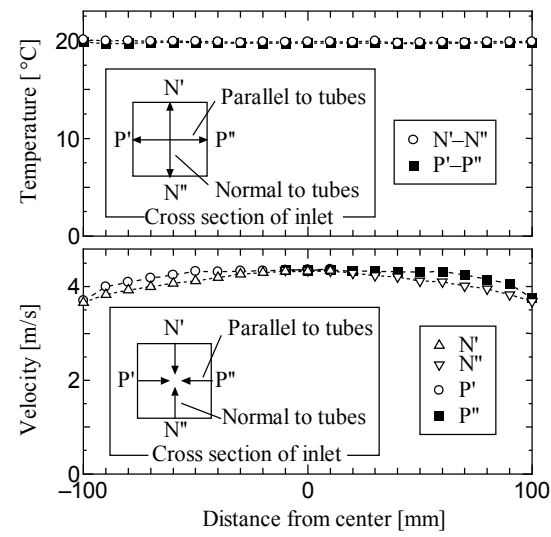

(a) Inlet flow

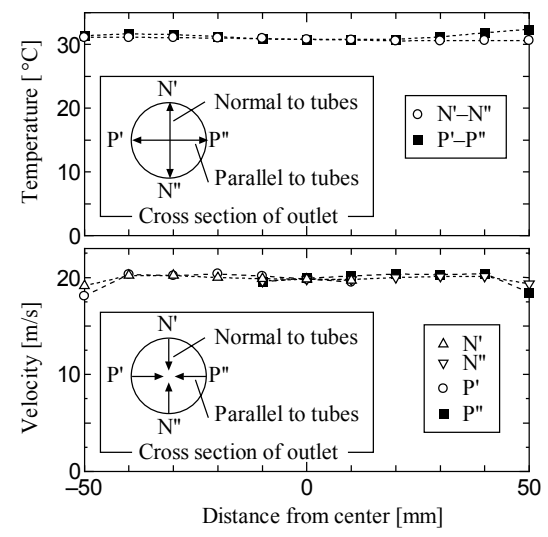

(b) Outlet flow

Fig.13 Typical experimental results for air flow measurement.

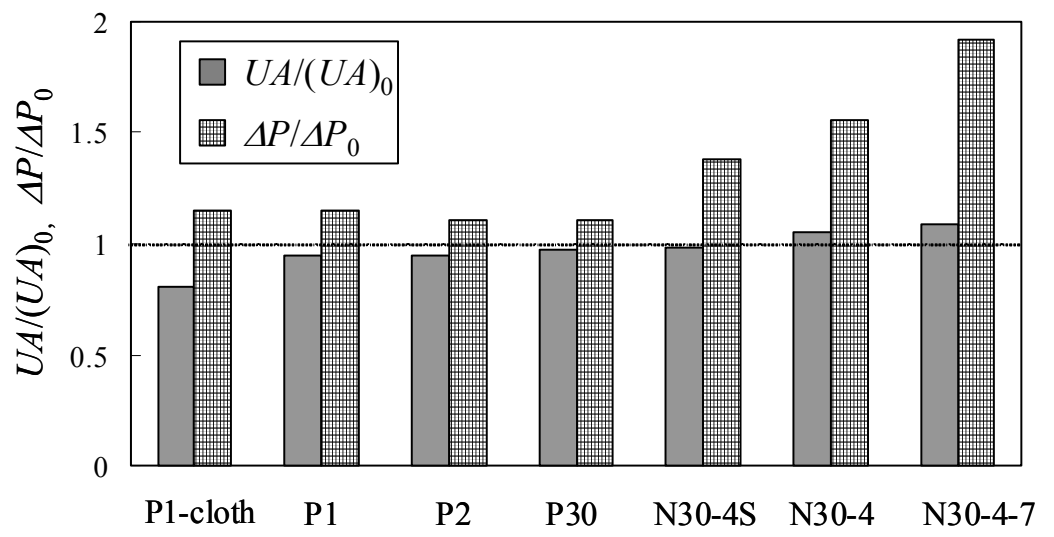

Fig.14 Summary of experimental results. 
obtained for the case where the fin was simply in contact with the fourth row of the tube bank (N30-4S), while $(U A) /(U A)_{0}>1$ was obtained for the case where the fin was installed in better contact with the heat transfer tube (N30-4, N30-4-7). On the other hand, $\Delta P$ for these cases increased greater than $\Delta P_{0}$ by $56-92 \%$.

\section{Discussion}

Contrary to the numerical analysis, considerable increment in $U A$ was not observed in the experiment. This can be attributed to the thermal contact resistance between the tube wall and the fin. Actually, the surface of the carbon fiber sheet is so rough that contact area between the sheet and tube surface is not large.

To ensure the contact between sheet and tube and not to damage to the device, sufficient tension was applied to the sheet. However, the distance between tubes in the heat exchanger was as small as $10 \mathrm{~mm}$. The frictional force between the tube wall and the sheet is so disturbing that force might not be applied to a part of the contact surface sufficiently. When $\lambda_{\mathrm{f}} \delta$ of the carbon fiber cloth is $0.013 \mathrm{~W} / \mathrm{K}, R_{\mathrm{c}}=3 \times 10^{-3} \mathrm{~m}^{2} \mathrm{~K} / \mathrm{W}$ is expected according to Fig. 5 (as plotted in the figure). Considering that the sheet material is fibrous and $R_{\mathrm{c}}$ between the metal surfaces is $5 \times 10^{-5}-4 \times 10^{-4} \mathrm{~m}^{2} \mathrm{~K} / \mathrm{W}^{(13)}$, it is possible to improve the value of $R_{\mathrm{c}}$ by modifying the installation method of the sheet. For example, by decreasing the contact resistance to $R_{\mathrm{c}}=4 \times 10^{-4}-5 \times 10^{-4} \mathrm{~m}^{2} \mathrm{~K} / \mathrm{W}$ and increasing $\lambda_{\mathrm{f}} \delta$ to $0.15 \mathrm{~W} / \mathrm{K}$, it is expected from Fig. 5 that the value of $U A$ improves by approximately $8 \%$.

In this study, the possibility of heat transfer enhancement is confirmed under low temperature range where not radiation heat transfer but convective heat transfer mainly takes place. It is expected that heat transfer enhancement become more effective with radiation heat transfer at higher temperature where the corrosive exhaust gas is emitted.

\section{Conclusions}

In this study, the extension of the heat transfer area using sheet material with high thermal conductivity was proposed for improvement of the efficiency of heat recovery from exhaust gases, and verification experiments were performed. Numerical analysis showed that the convective heat transfer rate increases with an increase in the Reynolds number. In addition, the numerical study indicates that increase in the pressure drop is inhibited compared with the case where fins are not installed. It was found that the performance of the fin is greatly affected by the thermal conductivity of the fin as well as the thermal contact resistance between the fin and the surface of the heat transfer tube.

Although the results of the verification experiment showed no improvement in the heat transfer rate with the installation of the fins, the improvement in the heat transfer rate with the installation of the fins was experimentally confirmed on the basis of the observation that the heat transfer rate decreased when a fin with an extremely low thermal conductivity was used. The improvement in the heat transfer rate was inhibited probably because of the thermal contact resistance of the fin. It was predicted that by decreasing $R_{\mathrm{c}}$ to $4 \times 10^{-4}-5 \times$ $10^{-4} \mathrm{~m}^{2} \mathrm{~K} / \mathrm{W}$ and increasing $\lambda_{\mathrm{f}} \delta$ to $0.15 \mathrm{~W} / \mathrm{K}$, the efficiency of heat recovery can be increased by approximately $8 \%$ in our experimental setup.

It is necessary to evaluate the lower limit for the thermal contact resistance between the sheet-like fin and the tube by optimizing the installation method and material of the fin and to evaluate the heat transfer enhancement in the temperature range in which the radiation heat transfer is dominant. In addition, from the viewpoint of energy conservation, the increase in the pump power must also be taken into account. If the waste energy is reduced and the efficiency of heat recovery is improved by the sheet method, the proposed technique would contribute to a significant reduction in $\mathrm{CO}_{2}$ emission in the steel industry and in 
chemical plants, which emit large quantities of thermal energy.

\section{References}

(1) Isshiki, N., Business Manual of System to Recover and Harness Waste Energy (in Japanese), (1981), p.21 and pp.224 - 225, Fujitec Corporation.

(2) Kagawa, M. and Nakayama, K., Numerical Simulation of Heat flow (in Japanese), (1990), pp.1-2, Morikita Publishing Co. Ltd.

(3) OECD Publishing ed., Energy balances of OECD countries 2004-2005, (2007), International Energy Agency.

(4) Joardar, A. and Jacobi, A.M., Heat Transfer Enhancement by Winglet-type Vortex Generator arrays in Compact Plain-fin-and-tube Heat Exchangers, International Journal of Refrigeration, Vol.31, Issue 1, (2008), pp.87-97.

(5) Mao, Y.W. and Ching, Y.H., Heat-transfer Enhancement in Fin-and-tube Heat Exchanger with improved Fin Design, Applied Thermal Engineering, Vol.29, (2009), pp.1050-1057.

(6) Paul, S.S., Ormiston, S.J. and Tachie, M.F., Experimental and Numerical Investigation of Turbulent Cross-flow in a staggered Tube Bundle, International Journal of Heat and Fluid Flow, Vol.29, Issue2, (2008), pp.387-414.

(7) Nakaso, K., Teshima, H., Yoshimura, A., Nogami, S., Hamada, Y. and Fukai, J., Extension of Heat Transfer Area using Carbon Fiber Cloths in Latent Heat Thermal Energy Storage Tanks, Chemical Engineering and Processing, vol.47, (2008), pp.879-885.

(8) Shih, T.H., Liou, W.W., Shabbir, A., Yang, Z. and Zhu, J., A New k-epsilon Eddy-Viscosity Model for High Reynolds Number Turbulent Flows - Model Development and Validation, Computers Fluids, vol.24, (1995), pp.227-238.

(9) Kader., B., Temperature and Concentration Profiles in Fully Turbulent Boundary Layers,

International Journal of Heat Mass Transfer, vol.24, (1981) pp.1541-15.

(10) Fishinden, M. and Saunder, O.A., Introduction to Heat Transfer, (1950), p.132, Oxford Press.

(11) Nakagawa, T., Obashi, M., Kuramoto, K., Hirata, M., Fujioka, H. and Mizuta, K., Development of a Cooling Roll for Continuous Annealing Line, Thermal Engineering Symposium, No930-41 (1993), pp.57-58.

(12) Shoji, M., Heat transfer Textbook, (1995), p.254, University of Tokyo Press.

(13) Salgon, J.J., A Mechanical and Geometrical approach to thermal contact resistance, International Journal of Heat Mass Transfer, vol.40, (1997), pp.1121-1129. 